\title{
Hormone replacement therapy and the endometrium
}

\author{
K M Feeley, M Wells
}

\begin{abstract}
Modern hormone replacement therapy (HRT) regimens contain oestrogen and progestogen, given either in a cyclical or continuous combined manner. Most endometrial biopsies from women on sequential HRT show weak secretory features. Approximately $15 \%$ show proliferative activity, although this figure may be less if more than nine days of progestogen is given in each cycle. A small proportion will show an inactive or atrophic endometrium. Up to $50 \%$ of biopsies from women on continuous combined HRT contain minimal endometrial tissue for histopathological analysis: this correlates well with an atrophic endometrium with no appreciable pathology. Of the $50 \%$ with more substantial material, approximately one half will show endometrial atrophy, and one half will show weak secretory features. Proliferative, menstrual, and pseudodecidual changes are rare. Approximately $20 \%$ of women given unopposed oestrogen for one year develop endometrial hyperplasia. The relative risk of endometrial carcinoma is two to three. This is dramatically reduced by the addition of progestogen to the regimen, but cyclical progestogen as part of a sequential HRT regimen does not completely eliminate the risk of carcinoma. The prevalence of endometrial hyperplasia associated with sequential HRT is $5.4 \%$, and that of atypical hyperplasia (endometrial intraepithelial neoplasia) is $0.7 \%$. Continuous combined HRT is not associated with the development of hyperplasia or carcinoma, and may normalise the endometrium of women who have developed complex hyperplasia on sequential HRT. The probability of a histopathologist finding clinically relevant pathology in an endometrial biopsy specimen of a patient on HRT is low and is more likely to be a manifestation of pre-existing disease. (F Clin Pathol 2001;54:435-440)
\end{abstract}

Keywords: endometrium; hormone replacement therapy; endometrial hyperplasia; endometrial carcinoma

Hormone replacement therapy (HRT) is used to treat vasomotor symptoms and conditions such as atrophic vaginitis in perimenopausal and postmenopausal women, and its long term use also has a role in reducing the incidence of osteoporosis and ischaemic heart disease in postmenopausal women. At least 20 million women in developed countries are estimated to be using HRT. ${ }^{1}$ Modern HRT preparations contain oestrogen and progestogen: progestogen is necessary to protect against the risk of endometrial hyperplasia ${ }^{2-5}$ and carcinoma ${ }^{6-10}$ conferred by long term unopposed oestrogen treatment. This risk is discussed more fully below. There are two commonly used regimens, sequential (cyclic) and continuous combined. Sequential HRT may be monthly or three monthly. Monthly sequential HRT comprises continuous oestrogen with progestogen added for 10-14 days/cycle or calendar month, producing monthly withdrawal bleeding. ${ }^{11}$ With three monthly sequential HRT, progestogen is given quarterly for 10-14 days, producing quarterly withdrawal bleeding. Continuous combined HRT involves both agents being used continuously: the growth promoting effects of oestrogen are opposed by progestogen, resulting in an atrophic endometrium. ${ }^{12}{ }^{13}$ This is advantageous in that it eliminates the withdrawal bleeding associated with sequential HRT, which can be a major reason for non-compliance. ${ }^{14-17} \mathrm{~A}$ woman who has had a hysterectomy can take oestrogen without a progestogen. An oestrogen implant is one option, and tablets, patches, or gel preparations are alternatives. A woman who has had endometrial ablation needs a progestogen, however, because some endometrial tissue may not have been destroyed by the procedure.

The histological assessment of the endometrium is an important part of the continuing follow up of patients taking HRT, and the histopathologist needs to be familiar with the appearances of the endometrium in a patient taking HRT. In this review, we discuss the effects of HRT on the endometrium and consider those appearances a histopathologist receiving endometrial biopsy specimens from patients on HRT is likely to encounter.

"Pipelle" samples and diagnostic difficulties with endometrial biopsies Many endometrial biopsy specimens from women on HRT will be obtained by the Pipel$1 \mathrm{e}^{\mathrm{TM}}$ sampler as an outpatient procedure. This method frequently results in very little tissue for histological analysis (up to $59 \%$ of biopsies in one study ${ }^{18}$ ). The amount of endometrial tissue required for a diagnosis by a histopathologist used to seeing biopsy specimens of this type is much less than that demanded by those unused to such biopsies. In many cases, a few short strips of endometrial-type epithelium or one or two endometrial-type glands may be all that is present. Rather than dismissing such 
samples as "inadequate for histological diagnosis", it may be useful to make a comment such as "there are a few strips of apparently inactive endometrial-type epithelium but no features to suggest hyperplasia or neoplasia". Nevertheless, there will be a substantial number of specimens that are truly unassessable. These fall into four categories: no tissue identified, tissue inadequate for diagnosis, no endometrium identified, and endometrium inadequate for diagnosis. Evidence shows that most patients whose biopsies yield minimal tissue have a thin, regular endometrium with an endometrial thickness not exceeding $7 \mathrm{~mm}$, as examined hysteroscopically or ultrasonically. The histopathologist can therefore be reassured that where the endometrial cavity has been entered and little or no endometrial tissue obtained, there is very little likelihood of important endometrial pathology being present. $^{19}$

Other difficulties that may be encountered with Pipelle sampling include the interpretation of focal changes of glandular tortuosity and crowding in disrupted endometrial fragments that are subject to considerable biopsy artifact. This is particularly true in the context of a secretory endometrium. The diagnosis of low grade cytological atypia can also be very difficult. Despite this, the Pipelle sampling method has been shown to be as accurate as conventional dilation and curettage in the diagnosis of endometrial pathology in premenopausal and postmenopausal women. ${ }^{20-22}$

\section{Endometrial histology in women on sequential HRT}

Endometrial samples from women on sequential HRT may show secretory, proliferative, or inactive patterns. Most samples will show weak secretory activity characterised by cytoplasmic vacuolation only. These samples will usually have been taken during the progestogen phase of the HRT regimen. Approximately 15\% of samples will show proliferative activity characterised by the presence of epithelial mitotic figures. Of these, approximately half will have been taken during the progestogen phase, and half during the oestrogen only phase. Women receiving progesterone for nine or more days/cycle show a significantly lower degree of proliferative activity. ${ }^{18}$ A small proportion (7-8\%) will show an inactive endometrium..$^{23}$ A distinction may be made between an inactive and an atrophic endometrium: all atrophic endometria are inactive, but an inactive endometrium may not be atrophic. Endometrial atrophy is less often seen in patients on sequential HRT than in those on continuous combined HRT. In pragmatic terms, there is little clinical relevance in distinguishing between an atrophic and an inactive endometrium. Endometrial hyperplasia may also occur with sequential HRT, and its prevalence is discussed further below.
Correlation between bleeding patterns and endometrial histology in patients on sequential HRT

In clinical practice, the onset of bleeding on or after day 11 of the progesterone phase is often taken as reassurance of a normal endometrium $^{25}$ and, conversely, irregular bleeding is often considered to be a sign of endometrial pathology. The endometrial response to sequential HRT is highly variable, however, and the classic histological criteria used to date the endometrium physiologically in relation to bleeding cannot be used in the context of the HRT exposed endometrium. ${ }^{26}$ A UK multicentre trial showed that most women start bleeding around the 13th day after starting progestogen, and that there is no correlation between the endometrial histology and the time of onset of bleeding. ${ }^{23} 27$ As regards endometrial hyperplasia, it was found that 37 of the 65 women with complex hyperplasia and four of the eight with atypia had regular bleeds after day $11 . .^{23}$ Another recent study on bleeding patterns in women on sequential HRT found a trend towards later withdrawal bleeding with secretory endometrium and earlier bleeding with inactive or atrophic endometrium, but with too much overlap for this to be of clinical relevance. ${ }^{28}$ It is therefore not possible to predict endometrial histology on the basis of bleeding patterns, and bleeding patterns cannot identify those rare cases where sequential HRT fails to protect the endometrium from the development of hyperplasia. Similarly, unexpected bleeding does not necessarily indicate endometrial pathology.

\section{Continuous combined HRT and the endometrium}

Studies have shown that continuous combined HRT induces an atrophic endometrium and eliminates bleeding in most postmenopausal women within six to 12 months. ${ }^{16-32}$ It is known that the continuous presence of progestogen in a regimen of continuous combined HRT causes downregulation of oestrogen and progestogen receptors, which in turn decreases sensitivity to hormonal stimulation. ${ }^{33}$ In addition, progestogen induces 17- $\beta$ dehydrogenase, which converts oestradiol to the less active oestrone, thereby reducing the oestrogenic stimulus. $^{34}$ It is not known which of these mechanisms predominates in producing endometrial atrophy in postmenopausal women on continuous combined HRT.

Early data on continuous combined HRT also suggested that it may be capable of transforming a hyperplastic endometrium into a state of atrophy. Staland reported on 22 women with endometrial hyperplasia who, after six months treatment with continuous combined HRT, were all found to have an atrophic endometrium. ${ }^{35}$

In a recent UK multicentre study, which is the largest to date reporting on endometrial histology in postmenopausal women taking continuous combined HRT, endometrial biopsy specimens were assessed after nine months of continuous combined HRT in two groups of women: those who had previously 
received sequential HRT, and those who had received no previous HRT. ${ }^{23}$ Women with endometrial hyperplasia without atypia were allowed to continue in the study and to receive study medication. The study reported no cases of endometrial hyperplasia: this supports the findings of previous studies using continuous combined HRT. ${ }^{52}{ }^{36-38}$ All of the women with complex hyperplasia on sequential HRT reverted to normal endometrial patterns after continuous combined HRT. This supports the earlier findings of Staland. ${ }^{35}$ No cases of endometrial malignancy were reported.

The post-treatment biopsies in this study were "unassessable" in $46 \%$ of previously untreated women, and in $37 \%$ of women who had previously received sequential HRT. This is broadly in support of previous studies, which have shown that more than $50 \%$ of biopsy specimens from postmenopausal women on continuous combined HRT are unassessable. ${ }^{16} 17313940$ Those post-treatment biopsies that were assessable showed similar features in both groups, with approximately half showing atrophy and half showing low grade secretory changes. The latter were mainly manifested by a variable degree of cytoplasmic vacuolation, which presumably reflects the simultaneous stimulation of the endometrium by oestrogen and progestogen, analogous to the early luteal phase. Pseudodecidual or menstrual-type changes were rare, and only $1.8 \%$ of previously untreated women and $2.3 \%$ of women previously receiving sequential HRT showed proliferative activity. Once again, these findings support those of a previous study, in which proliferative activity was found in $3.6 \%$ of women who had been taking progestogen daily for 24 months. ${ }^{38}$ One possible explanation for the presence of proliferative activity in these few cases is that the relative dose of progestogen might have been inadequate to suppress totally the oestrogenic stimulation of the endometrium. Alternatively, endogenous factors, such as obesity, might contribute to persistent endometrial stimulation despite continuous combined HRT.

Therefore, the implications of this study ${ }^{23}$ are that continuous combined HRT is not associated with an increased risk of endometrial hyperplasia or malignancy, and indeed may normalise an endometrium showing pretreatment complex hyperplasia. This in turn implies that continuous combined HRT provides a reassuring degree of endometrial safety and is appropriate as a regimen for long term use in postmenopausal women.

\section{HRT and endometrial polyps}

Endometrial polyps are relatively common in women on HRT ${ }^{41-43}$ Most occur in women on sequential HRT, and show similar features to endometrial polyps found in the general female population. However, one study reported a higher prevalence of hyperplasia in endometrial polyps from women on HRT than controls: ${ }^{41}$ this suggests that careful histological evaluation is warranted in cases of polyps from women on HRT. Hyperplasia in HRT associated polyps is not as common as hyperplasia in tamoxifen associated polyps, and those other features characteristically seen in tamoxifen associated polyps, such as metaplasia and stromal fibrosis, are less commonly seen in polyps from women on HRT. ${ }^{42}$

Endometrial polyps are less common in women on continuous combined HRT, but have been reported. ${ }^{19}$ Rarely, women reporting breakthrough bleeding after having achieved prolonged amenorrhoea on continuous combined HRT will be found to have an endometrial polyp. ${ }^{44}$ Such cases always warrant biopsy and histological evaluation, however, because adenocarcinoma can also occur. ${ }^{44}$

\section{HRT and endometrial hyperplasia and neoplasia}

Before any discussion of HRT and the risk of endometrial carcinoma, two important points should be remembered. First, it has been shown clearly that the endometrial lesion associated with a significant risk of carcinoma is atypical hyperplasia. ${ }^{45} 46$ The morphological hallmark of endometrial precancer is cytological atypia, although it is now recognised that the lesion also has characteristic architectural features that equate with monoclonality. ${ }^{47}$ There is general acceptance that atypical hyperplasia is a neoplastic process, quite distinct from true hyperplasia. Hence, use of the term "endometrial intraepithelial neoplasia", or EIN, has been advocated. ${ }^{48}$ In contrast to atypical hyperplasia, it may be argued that true endometrial hyperplasia represents the physiological response of the endometrium to excess oestrogen, and therefore has a low risk of neoplastic transformation. The histological changes associated with the current diagnoses of simple and complex hyperplasia merely reflect different patterns of the hyperplastic endometrial response to excess oestrogen, whereas the development of precancer requires other, as yet unidentified, cofactors.

Second, postmenopausal women, who represent the major group of patients taking HRT have, by virtue of their age, a background prevalence (albeit low) of endometrial precancer and cancer, which must be taken into account when assessing the risks of HRT. In a study of 801 asymptomatic women, Archer et al found a prevalence of endometrial hyperplasia of $5.2 \%$ and of atypical hyperplasia of $0.6 \%$, with one case of endometrial carcinoma. ${ }^{49}$ Korhonen et al evaluated endometrial biopsy specimens from 2964 perimenopausal and postmenopausal women who were candidates for HRT, and found $68.7 \%$ of these to be atrophic, $23.5 \%$ proliferative, $0.5 \%$ secretory, and $0.6 \%$ to be hyperplastic ${ }^{50} ; 0.07 \%$ showed adenocarcinoma and $6.6 \%$ had insufficient tissue for classification. The authors concluded that the low yield of endometrial carcinoma indicated that biopsy was unnecessary before starting HRT in asymptomatic women.

\section{UNOPPOSED OESTROGEN TREATMENT}

An association between endogenous hyperoestrogenism and endometrial hyperplasia was documented in the 1940 s and 1950 s before the introduction of exogenous oestrogen 
treatment. ${ }^{51-53}$ The association between exogenous oestrogen treatment and endometrial carcinoma was documented in the 1970s, and since then has been confirmed repeatedly. ${ }^{54-65}$ The reported risk ratio for endometrial carcinoma in women taking unopposed oestrogen has varied from $2.3^{65}$ to $10 .^{62}$ The risk increases with increasing daily dose and duration of treatment. ${ }^{52}$ 59-62 The risk persists for many years after oestrogen treatment has been stopped. ${ }^{56164}$ Oestrogen related endometrial carcinoma risks are greater in lean than in overweight women, implying that exogenous oestrogens have an additive (rather than multiplicative) effect on endometrial carcinogenesis, and suggesting the existence of an upper risk threshold or the existence of some limiting factor (for example, sex hormone receptors) that impedes the continued efficacy of the combined oestrogenic stimulus of obesity and exogenous oestrogen beyond a certain level. ${ }^{66}$ Data also suggest that the risk of endometrial carcinoma is reduced among women who have used oral contraceptives. ${ }^{63}{ }^{66}$ It may be that oral contraceptive use renders the endometrium less susceptible to hormonal carcinogenesis.

Studies have shown repeatedly that there is an association between unopposed oestrogen treatment and endometrial hyperplasia, ${ }^{2-56768}$ and some have shown an association between the dose of oestrogen and the prevalence of hyperplasia..$^{2-4}$ The "postmenopausal estrogen/ progestin intervention (PEPI) trial" was a large, prospective, randomised, double blind study, which found that women assigned to oestrogen alone $(0.625 \mathrm{mg}$ conjugated equine oestrogen) were significantly more likely to develop simple $(27.7 \%)$, complex $(22.7 \%)$, or atypical hyperplasia $(11.7 \%)$ than those given placebo (simple $0.8 \%$, complex $0.8 \%$, atypical $0 \% ; \mathrm{p}<0.001) .{ }^{67}$ This study demonstrated the necessity for baseline and annual endometrial biopsy samples when a high dose of unopposed oestrogen such as this is used.

SEQUENTIAL HRT

It is well established that the addition of a progestogen to an HRT regimen substantially reduces the risk of endometrial carcinoma. ${ }^{35786769}$ Although some studies have reported no significant differences in the incidence of endometrial carcinoma among women on combined HRT compared with women not taking HRT, ${ }^{6-864}$ recent studies have suggested that the cyclical addition of progestogen to HRT does not completely eliminate the risk. Beresford et al found that the relative risk of endometrial carcinoma in women using a sequential combined regimen of oestrogen and at least 10 days of progestogen was 1.3 (confidence interval (CI), 0.8 to 2.2 ), increasing to 2.5 (CI, 1.1 to 5.5 ) with five or more years of use, compared with an odds ratio of 1.0 for women who had never used hormones. ${ }^{9}$ This study also showed that fewer than 10 days of progestogen/cycle gave a relative risk of 3.1 (CI, 1.17 to 5.7), and, when used for five or more years, a relative risk of 3.7 (CI, 1.7 to 8.2). Weiderpass et al found that women receiving a sequential combined regimen of oestrogen and fewer than 16 days progestogen for five or more years had a relative risk of carcinoma of 1.6, compared with controls. ${ }^{70}$ Pike et al found no significant increase in the risk of carcinoma in women receiving combined and sequential HRT, the latter with 10 or more days of progestogen/ cycle; however, in women on sequential HRT with less than 10 days progestogen/cycle, an increased risk of carcinoma of similar magnitude to that of women on unopposed oestrogen was found. ${ }^{10}$

The PEPI trial found that women on sequential HRT showed a tendency to develop hyperplasia (simple $3.4 \%$, complex $1.7 \%$, atypical $0 \%$ ), but the numbers were small and the differences between regimens were not significant. ${ }^{67}$ The PEPI trial also reported that of 36 women who developed oestrogen induced hyperplasia during the trial, 34 reverted to normal on discontinuation of the oestrogen and introduction of progestogen.

In the UK multicentre study, endometrial biopsy data were generated for women treated with sequential HRT for a mean duration of 2.5 years (range, $1-6$ years). ${ }^{23}$ Complex hyperplasia was found in $5.4 \%$, and atypical hyperplasia in $0.7 \%$. It is possible that these figures, which are higher than those reported previously, may reflect the duration of the study, which had a longer mean duration of treatment than previous studies. There were no cases of endometrial carcinoma. Most (76.8\%) of the biopsies showing hyperplasia were taken during the progestogen phase of the treatment cycle, whereas $17.8 \%$ were taken during treatment with oestrogen alone. There were no significant differences in the prevalence of hyperplasia between regimens containing 10 or 12 days progestogen. Hyperplasia was found to be significantly more prevalent with regimens containing levonorgestrel than those containing norethisterone acetate $(7.3 \% \quad v \quad 4.2 \%)$. Hyperplasia was also more prevalent with lower doses of progestogen than with higher dose treatment. These results suggest that the risk of endometrial hyperplasia might be increased in women treated with sequential HRT containing lower doses of progestogen.

Broadly similar results were seen in a more recent study that compared a long cycle (three monthly) sequential HRT regimen with a monthly cycle, progestogen being given for 10 days in each cycle: there was a higher incidence of hyperplasia, and one case each of atypical hyperplasia and carcinoma, in the long cycle group, compared with the monthly cycle group. In addition, the long cycle group had a more irregular bleeding pattern, and correspondingly a higher drop out rate. ${ }^{71}$

\section{CONTINUOUS COMBINED HRT}

Endometrial carcinoma has been reported only rarely in women taking continuous combined HRT regimens. ${ }^{44}{ }^{72-75}$ In most cases, however, the women had a history of unopposed oestrogen or sequential HRT use with less than 10 days of progestogen, or risk factors such as a family history of endometrial carcinoma. ${ }^{44} 72$ As 
discussed above, the largest study to date reporting endometrial histology in postmenopausal women on continuous combined HRT showed no cases of endometrial hyperplasia or malignancy with an atrophic endometrium being induced in more than two thirds of women during a nine month treatment period. ${ }^{23}$ All the women with complex hyperplasia on sequential HRT who completed the study reverted to non-hyperplastic endometrial patterns.

In the three years of the PEPI trial there were no recorded cases of complex hyperplasia in women on continuous combined HRT, compared with $1.7 \%$ of 118 women treated with sequential HRT and $0.8 \%$ of 119 women treated with placebo. ${ }^{67} \mathrm{~A}$ further recent study of continuous combined HRT over a two year period reported no cases of endometrial hyperplasia ${ }^{38}$ confirming the findings of earlier studies. $^{5} 323637$

\section{Conclusions}

Most endometrial biopsies from women on sequential HRT show weak secretory features, and a minority show proliferative or inactive endometrium.

Many (up to $50 \%$ ) biopsies from women on continuous combined HRT contain minimal tissue for examination. Approximately $50 \%$ of more substantial biopsies show endometrial atrophy, and approximately $50 \%$ show weak secretory features.

Providing the uterine cavity has been sampled, a biopsy containing minimal or no endometrial tissue in a postmenopausal woman on HRT is reassurance that there is no clinically relevant endometrial pathology.

There is no correlation between bleeding on HRT and endometrial histology.

Unopposed oestrogen will cause endometrial hyperplasia in approximately $20 \%$ of women after one year of treatment. The relative risk of carcinoma is two to three.

Combining progestogen with oestrogen substantially reduces the risk of atypical endometrial hyperplasia and adenocarcinoma.

Sequential HRT is associated with a low risk of endometrial hyperplasia and atypical hyperplasia (approximately 1\% for atypical hyperplasia). Regimens containing less than 10 days progestogen or lower doses of progestogen may confer a higher risk of hyperplasia, atypical hyperplasia, and adenocarcinoma.

Continuous combined HRT is not associated with the development of endometrial hyperplasia or malignancy.

The likelihood of the histopathologist finding clinically relevant pathology in the endometrial biopsy of a woman taking HRT is low and is more likely to be a manifestation of pre-existing disease.

1 Beral V, Banks E, Reeves G, et al. Use of HRT and the subsequent risk of cancer. F Epidemiol Biostat 1999;4:191-210.

2 Whitehead MI, King RJB, McQueen J, et al. Endometrial histology and biochemistry in climacteric women during oestrogen and progestogen therapy. $\mathcal{F} R$ Soc Med 1979;72: 322-7.

3 Paterson MEL, Wade-Evans T, Sturdee DW, et al. Endometrial disease after treatment with oestrogens and pro-
gestogens in the climacteric. BMf 1980;280:822-4.
4 Gelfand MM, Ferenczy A. A prospective 1-year study of estrogen and progestin in postmenopausal women: of estrogen and progestin in postmenopausal women: 402 .

5 Woodruff JD, Pickar JH, for the Menopause Study Group. Incidence of endometrial hyperplasia in postmenopausal women taking conjugated estrogens (Premarin) with medroxyprogesterone acetate or conjugated estrogens alone. Am f Obstet Gynecol 1994;170:1213-23.

6 Hammond CB, Jelovsek FR, Lee KL, et al. Effects of long term estrogen replacement therapy. II. Neoplasia. Am 7 Obstet Gynecol 1979;133:537-47.

7 Persson I, Adami HO, Bergkvist L, et al. Risk of endometrial cancer after treatment with oestrogens alone or in conjunction with progestogens: results of a prospective study. BMF tion with progesto

8 Voight LF, Weiss NS, Chu J, et al. Progestagen supplementation of exogenous oestrogens and risk of endometrial cancer. Lancet 1991:338:274-7.

9 Beresford SAA, Weiss NS, Voight LF, et al. Risk of endometrial cancer in relation to oestrogen combined with cyclic progestagen therapy in postmenopausal women. Lancet 1997;349:458-61

10 Pike MC, Peters RK, Cozen W, et al. Estrogen-progestin replacement therapy and endometrial cancer. 7 Natl Cancer Inst 1997;89:1110-16.

11 Whitehead MI, Hillard TC, Crook D. The role and use of progestogens. Obstet Gynecol 1990;75:59S-76S

12 Hawthorn RJS, Spowart K, Walsh D, et al. The endometrial status of women on long-term continuous combined hormone replacement therapy. Br $\mathcal{f}$ Obstet Gynaecol 1991;98:939-42.

13 Hillard TC, Siddle NC, Whitehead MI. Continuous combined conjugated equine estrogen-progestagen therapy: effects of medroxyprogesterone acetate and norethindrone acetate on bleeding patterns and endometrial histologic diagnosis. Am f Obstet Gynecol 1992;167:1-

14 Barentsen R, Groeneveld FP, Bareman FP, et al. Women's opinion on withdrawal bleeding with hormone replacement therapy. Eur f Obstet Gynecol Reprod Biol 1993;51:203-7.

15 Hahn RG. Compliance considerations with estrogen replacement: withdrawal bleeding and other factors. $A m$ F Obstet Gynecol 1989;161:1854-8.

16 Ravnikar VA. Barriers for taking long-term hormone replacement therapy: why do women not adhere to therapy? European Menopause fournal 1996;3(suppl 2): (10-3.

17 Rees M. On menstrual bleeding with hormone replacement therapy. Lancet 1994;343:250.

18 Moyer DL, de Lignieres B, Driguez P, et al. Prevention of endometrial hyperplasia by progesterone during long-term estradiol replacement: influence of bleeding pattern and secretory changes. Fertil Steril 1993;59:992-7.

19 Piegsa K, Calder A, Davis JA, et al. Endometrial status in post-menopausal women on long-term continuous combined hormone replacement therapy (Kliofem). A comparative study of endometrial biopsy, outpatient hysterosparative study of endometrial biopsy, outpatient hysteroscopy and transvaginal ultra

20 Stovall TG, Photopulos GJ, Poston WM, et al. Pipelle sampling in patients with known endometrial carcinoma. Obstet Gynecol 1991;77:954-6.

21 Fothergill DJ, Brown VA, Hill AS. Histological sampling of the endometrium: comparison between formal curettage and the Pipelle sampler. Br f Obstet Gynaecol 1992;99:779-

22 Batool T, Reginald PW, Hughes JH. Outpatient Pipelle endometrial biopsy in the investigation of post-menopausal bleeding. Br 7 Obstet Gynaecol 1994;101:545-6.

23 Sturdee DW, Ulrich LG, Barlow DH, et al. The endometrial response to sequential and continuous combined oestrogen-progestogen replacement therapy. $\mathrm{Br} \mathcal{F}$ Obstet oestrogen-progestogen replace
Gynaecol 2000;107:1392-400.

24 Archer DF, Pickar JH, Bottiglioni F. Bleeding patterns in postmenopausal women taking continuous combined or sequential regimens of conjugated oestrogens with medroxyprogesterone acetate. Obstet Gynecol 1994;83: 686-92.

25 Padwick ML, Pryse-Davies J, Whitehead MI. A simple method for determining the optimal dose of progestin in postmenopausal women receiving oestrogens. $N$ Engl $f$ Med 1986;315:930-4.

26 Habiba MA, Bell SC, Al-Azzawi F. Endometrial responses to hormone replacement therapy: histological features compared with those of late luteal phase endometrium. Hum Reprod 1998;13:1674-82.

27 Sturdee DW, Barlow DH, Ulrich LG, et al. Is the timing of withdrawal bleeding a guide to endometrial safety during sequential oestrogen-progestogen replacement therapy? Lancet 1994;344:979-82

28 Burch D, Bieshuevel E, Smith S, et al. Can endometrial protection be inferred from the bleeding pattern on combined cyclical hormonal replacement therapy. Maturitas 2000;34: $155-60$

29 Obel EB, Munk-Jensen N, Svenstrup B, et al. A two-year, double-blind controlled study of the clinical effect of combined and sequential postmenopausal replacement therapy and steroid metabolism during treatment. Maturitas 1993; 16:13-21.

30 Mattsson LÅ, Culberg G, Samsioe G. Evaluation of a continuous oestrogen-progestogen regimen for climacteric complaints. Maturitas 1982;4:95-102. 
31 Sporrong T, Hellgren M, Samsioe G, et al. Comparison of four continuously administered progestogens plus estradio combinations for climacteric complaints. $\mathrm{Br} \mathcal{F}$ Obste $88 ; 95: 1042-8$

32 Staland B. Continuous treatment with a combination of estrogen and gestagen - a way of avoiding endometrial stimulation. Clinical experience with Kliogest ${ }^{\circledR}$. Acta Obstet Gynaecol Scand Suppl 1985;130:29-35.

33 King RJB, Whitehead MI, Campbell S, et al. Biochemical studies on the endometrium from postmenopausal women receiving hormone replacement therapy. Postgrad Med $f$ 1978;54:65-8.

34 Casper RF. Regulation of estrogen-progestagen receptors in the endometrium. Int F Fertil Menopausal Stud 1996;23:31-9.

35 Staland B. Continuous treatment with natural oestrogens and progestagens. A method to avoid endometrial stimulation. Maturitas 1981;3:145-56.

36 Udoff L, Langenberg P, Adashi EY. Combined continuous hormone replacement therapy: a critical review. Obstet Gynecol 1995;86:306-16.

37 Stadberg E, Mattson LÅ, Uvebrant M. $17 \beta$-estradiol and norethisterone acetate in low doses as continuous com-
bined hormone replacement therapy. Maturitas 1996;23: bined

38 Nand SL, Webster MA, Baber R, et al, for the Ogen/Provera Study Group. Bleeding pattern and endometrial changes during continuous combined hormone replacemen therapy. Obstet Gynecol 1998;91:678-84.

39 Weinstein L, Bewtra C, Gallagher C. Evaluation of a continuous combined low-dose regimen of estrogenprogestin for treatment of the menopausal patient. Am $f$ Obstet Gynecol 1990;162:1534-42.

40 Spowart KJM, Walsh DJ, Hawthorn RJS, et al. Hysteroscopic assessment of the effects of a continuous combined oestrogen-progestagen regimen on the endometrium of postmenopausal women. Gynaecological Endoscopy 1992;1: 33-5.

41 Orvieto R, Bar-Hava I, Dicker D, et al. Endometrial polyps during menopause: characterization and significance. Acta during menopause: characterization

42 Kennedy MM, Baigrie CF, Manek S. Tamoxifen and the endometrium: review of 102 cases and comparison with HRT-related and non-HRT-related endometrial pathology. Int F Gynecol Pathol 1999;18:130-7.

43 Maia H, Jr, Barbosa IC, Marques D, et al. Hysteroscopy and transvaginal sonography in menopausal women receiving hormone replacement therapy. $\mathcal{F}$ Am Assoc Gynecol Laparosc 1996;4:13-18.

44 Leather AT, Savvas M, Studd JW. Endometrial histology and bleeding patterns after 8 years of continuous combined estrogen and progestogen therapy in postmenopausal women. Obstet Gynecol 1991;78;1008-10.

45 Kurman RJ. The behaviour of endometrial hyperplasia. A long-term study of "untreated" hyperplasia in 170 patients. Cancer 1985;56:403-12.

46 Ferenczy A, Gelfand M. The biologic significance of cytologic atypia in progestogen-treated endometrial hypercytologic atypia in progestogen-treated endom
plasia. Am $\mathcal{f}$ Obstet Gynecol 1989;160:126-31.

47 Mutter GL, Baak JPA, Crum CP, et al. Endometrial precancer diagnosis by histopathology, clonal analysis, and cer diagnosis by histopathology, clonal analysis,

48 Mutter GL. Endometrial intraepithelial neoplasia (EIN): will it bring order to chaos? The endometrial collaborative group. Gynecol Oncol 2000;76:287-90.

49 Archer DF, McIntyre-Seltman K, Wilborn WW, et al. Endometrial morphology in asymptomatic postmenopausal women. Am f Obstet Gynecol 1991;165:317-22

50 Korhonen MO, Symons JP, Hyde BM, et al. Histologic classification and pathologic findings for endometrial biopsy specimens obtained from 2964 perimenopausal and postmenopausal women undergoing treatment for continupostmenopaus as reprerint Am $\mathcal{f}$ Obstet Gynecol 1997;176:377-80.

51 Gusberg SB. Precursors of corpus carcinoma. Estrogens and adenomatous hyperplasia. Am $\mathcal{f}$ Obstet Gynecol 1947;54:905-27.

52 Mansell H, Hertig AT. Granulosa-theca cell tumours and endometrial carcinoma: a study of their relationship and a survey of 80 cases. Obstet Gynecol 1955;6:385-94.

53 Jackson RL, Dockerty MB. The Stein Leventhal syndrome: analysis of 43 cases with special reference to association with endometrial carcinoma. Am f Obstet Gynecol 1957;73 161-73.
54 Smith DC, Prentice R, Thompson DJ, et al. Association of exogenous estrogen and endometrial carcinoma. $N$ Engl $\mathcal{F}$ Med 1975;293:1164-7.

55 Ziel HK, Finkle WD. Increased risk of endometrial carcinoma among users of conjugated estrogens. $N$ Engl f Med 1975;293:1167-70.

56 Mack TM, Pike MC, Henderson BE, et al. Estrogens and endometrial cancer in a retirement community. $N$ Engl $f$ Med 1976;294:1262-1267.

57 Weiss NS, Szekely DR, Austin DF. Increasing incidence of endometrial cancer in the United States. $N$ Engl f Med 1976;294:1259-62.

58 Antunes CMF, Stolley, Rosenheim NB, et al. Endometrial cancer and estrogen use. Report of a large case-control study. N Engl F Med 1979;300:9-13.

59 Shapiro S, Kaufman DW, Sloane D, et al. Recent and past use of conjugated estrogens in relation to adenocarcinoma of the endometrium. N Engl F Med 1980;303:485-9.

60 Spengler RF, Clarke RA, Woolever CA, et al. Exogenous estrogens and endometrial cancer: a case control study and assessment of potential biases. Am f Epidemiol 1981;114: 497-506

61 Shapiro S, Kelly JP, Rosenberg L, et al. Risk of localized and widespread endometrial cancer in relation to recent and discontinued use of conjugated estrogens. $N$ Engl $\mathcal{F ~ M e d ~}$ 1985;313:969-72.

62 Paganini-Hill A, Ross RK, Henderson BE. Endometrial cancer and patterns of oestrogen replacement therapy. $\mathrm{Br} \mathcal{F}$ Cancer 1989;59:445-7.

63 Rubin GL, Peterson HB, Lee NC, et al. Estrogen replacement therapy and the risk of endometrial cancer: remaining controversies. Am f Obstet Gynecol 1990;162: $148-54$.

64 Brinton LA, Hoover RN, and the Endometrial Cancer Collaborative Group. Estrogen replacement therapy and endometrial cancer risk: unresolved issues. Obstet Gynecol 1993;81:265-71.

65 Grady D, Gebrestsadik T, Kerlikowske K, et al. Hormone replacement therapy and endometrial cancer risk: a meta-analysis. Obstet Gynecol 1995;85:304-13.

66 Levi F, La Vecchia C, Gulie C, et al. Oestrogen replacement treatment and the risk of endometrial cancer: an assessment of the role of covariates. Eur $\mathcal{F}$ Cancer 1993;29A: 1445-9.

67 The Writing Group for the PEPI Trial 1996. Effects of hormone replacement therapy on endometrial histology in postmenopausal women. The postmenopausal estrogen/ progestin interventions (PEPI) trial. FAMA 1996;275:3705 .

68 Cushing KL, Weiss NS, Voight LF, et al. Risk of endometrial cancer in relation to use of low-dose, unopposed oestrogens. Obstet Gynecol 1998;91:35-9.

69 Persson I, Yuen J, Bergkvist L, et al. Cancer incidence and mortality in women receiving estrogen and estrogenprogestin replacement therapy-long term follow-up of a Swedish cohort. Int f Cancer 1996;67:327-32.

70 Weiderpass E, Adami HO, Baron JA, et al. Risk of endometrial cancer following estrogen replacement with and without progestins. F Natl Cancer Inst 1999;91:1131-7.

71 Bjarnason K, Cerin A, Lindgren R, et al. Adverse endometrial effects during long cycle hormone replacement therapy. Scandinavian long cycle study group. Maturitas 1999;32:161-70

72 McGonigle KF, Karlan BY, Barbuto DA, et al. Development of endometrial cancer in women on estrogen and progestin hormone replacement therapy. Gynecol Oncol 1994;55: $126-32$.

73 Dören M, Schneider HPG. Long term compliance of continuous combined oestrogen and progestogen replacement in postmenopausal women. Maturitas 1996;25:99105.

74 Comerci JT, Fields AL, Runowicz CD, et al. Continuous low-dose combined hormone replacement therapy and the risk of endometrial cancer. Gynecol Oncol 1997;64:425-30.

75 Ulrich LG. Accumulated knowledge of Kliogest ${ }^{\circledR}$ safety aspects. Br f Obstet Gynaecol 1996;103:99-103. 